\title{
BADANIA WPEYWU ZUŻYCIA OSTRZY W GLOWICY FREZOWEJ NA CHROPOWATOŚĆ POWIERZCHNI OBROBIONEJ STOPU TYTANU
}

\begin{abstract}
Badania odnoszą się do prób frezowania powierzchni płaskich stopu tytanu WT22 (Ti-6Al-5Mo-5V-1Cr-1Fe) o twardości 40 HRC ostrzami z węglików spiekanych powlekanych azotkiem tytanu. Dobór parametrów frezowania i metod pomiarowych był związany z analizą zjawisk przykrawędziowych, zachodzących podczas obróbki narzędziami wieloostrzowymi, które tworzą powierzchnię obrobioną w wyniku wzajemnie nakładających się oddziaływań. Do badań zastosowano głowicę frezową z ośmioma płytkami wymiennymi o nowoczesnej konstrukcji wierzchołka ostrza w postaci powierzchni dogładzającej Abs. Badania zużycia ostrzy i chropowatości powierzchni obrobionej przeprowadzono dla trzech prędkości posuwu, przy uwzględnieniu bicia osiowego ostrzy.
\end{abstract}

Słowa kluczowe: frezowanie powierzchni płaskiej, zużycie ostrza, chropowatość powierzchni obrobionej, obróbka stopu tytanu

\section{Wprowadzenie}

Korzystne właściwości mechaniczne i chemiczne stopów tytanu wpływają na ich szerokie zastosowanie w przemyśle i medycynie. Właściwości stopów tytanu, takie jak korzystny stosunek wytrzymałości do ciężaru, odporność na korozję i wysokie temperatury powodują jednak trudności w ich obróbce - przyspieszone zużycie narzędzia, drgania czy małą wydajność skrawania (metal removal rate MRR) [1-4]. Głównymi powodami względnej małej obrabialności stopów tytanu jest ich mała przewodność cieplna, wysoka reaktywność chemiczna i mała wartość modułu Younga [5].

Badania skrawalności stopów tytanu są prowadzone niezależnie dla prób toczenia, frezowania i wiercenia, gdyż przykładowo otrzymane wyniki dla toczenia nie mają przełożenia na frezowanie, gdzie przerywany charakter obróbki powo-

\footnotetext{
${ }^{1}$ Łukasz Żurawski, Politechnika Koszalińska, e-mail: lukasz.zurawski@tu.koszalin.pl

2 Borys Storch, Politechnika Koszalińska, e-mail: borys.storch@tu.koszalin.pl

3 Autor do korespondencji/corresponding author: Anna Zawada-Tomkiewicz, Politechnika Koszalińska, ul. Racławicka 15-17, tel.: 943478 451, e-mail: anna.zawada-tomkiewicz@tu.koszalin.pl
} 
duje wiele niekorzystnych zjawisk na ostrzu narzędzia skrawającego [6]. Podczas frezowania ostrze skrawające jest poddawane cyklicznemu obciążeniu. Zjawisko to niekorzystnie wpływa na trwałość narzędzia, siły skrawania, jakość powierzchni, dokładność wymiarów i ekonomikę obróbki skrawaniem. Siły skrawania, temperatura w otoczeniu krawędzi skrawającej ujawniają odrywające się cienkie wióry, ze skłonnością do zacierania się i adhezji w otoczeniu krawędzi skrawającej. Rozwiązaniem jest rozkład naddatku na kilka dosuwów, aby ograniczyć nadmierne wykruszanie otoczenia wierzchołka ostrza powodującego skrócenie trwałości płytek skrawających. Obróbka wymaga także ograniczenia prędkości skrawania. Oznacza to odpowiedni dobór narzędzi skrawających i parametrów obróbki. W tym celu należy przeprowadzić dobór parametrów skrawania w odniesieniu do stosowanej operacji.

W artykule zostaną zaprezentowane badania skrawalności stopu tytanu dla kryterium zużycia narzędzia i chropowatości powierzchni obrobionej. Ponadto zostanie przedstawiony wpływ posuwu na zużycie ostrzy w głowicy frezowej oraz chropowatość powierzchni stopu tytanu.

\section{Metodyka badań frezowania stopu tytanu}

Celem badań było przeprowadzenie prób frezowania dla zmiennych wartości posuwu na ostrze oraz obserwacja zużycia ostrzy w głowicy frezowej. Narzędziem była głowica frezowa nasadzana do frezowania powierzchni płaskich.
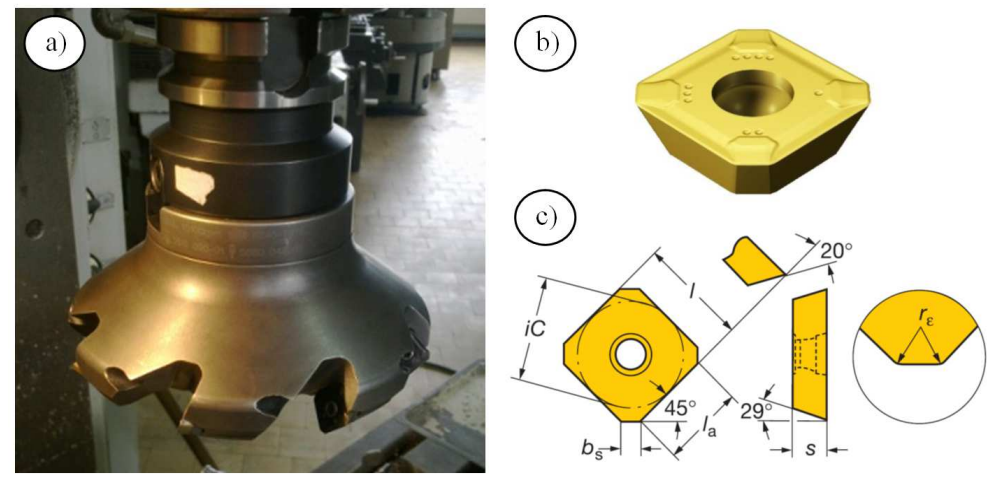

Rys. 1. Głowica frezowa R245-125Q40-12M (a), płytka wymienna R24512T3M-PM 4230 (b) oraz geometria jej ostrza (c)

Fig. 1. Face milling cutter R245-125Q40-12M (a), cutting insert (R24512T3M-PM 4230) (b) and geometry of a milling insert (c)

Próby frezowania przeprowadzono na frezarce uniwersalnej FWD32J o mocy silnika 7,1 kW, głowicą frezową R245-125Q40-12M z ośmioma płytkami wymiennymi do frezowania powierzchni płaskich Sandvik R245-12T3M-PM 4230 (rys. 1). Dla każdej z prób frezowania zamocowano w głowicy nowe płytki 
skrawające, a następnie dla każdego z ostrzy wykonano pomiary bicia osiowego płytek wymiennych w głowicy frezowej. Do pomiaru użyto czujnika z zamontowaną płaską końcówką pomiarową Sylvac $\mu$ S229 o dokładności $0,001 \mathrm{~mm}$ i zakresie pomiarowym 0-12,5 $\mathrm{mm}$.

Zadaniem w badaniach było opisanie jakości powierzchni obrobionej za pomocą parametrów $R a$ i $R z$ po frezowaniu stopu tytanu, oznaczonego jako WT22 (Ti-6Al-5Mo-5V-1Cr-1Fe), o twardości około $40 \mathrm{HRC}$, przygotowanego jako próbki o wymiarach $\emptyset 50 \times 250 \mathrm{~mm}$. Z uwagi na możliwości obrabiarki i oprzyrządowanie badanie przeprowadzono dla trzech posuwów na ostrze i trzech prędkości skrawania (tab. 1).

Tabela 1. Plan badań frezowania

Table 1. Research plan of milling tests

\begin{tabular}{|c|c|c|c|c|}
\hline \multirow{2}{*}{ Wielkość } & \multirow{2}{*}{ Miano } & \multicolumn{3}{|c|}{ Punkty planu eksperymentu } \\
\cline { 3 - 5 } & & 1 & 2 & 3 \\
\hline $\begin{array}{c}\text { Prędkość } \\
\text { obrotowa wrzeciona } n\end{array}$ & obr./min & 1190 & 375 & 470 \\
\hline Prędkość skrawania $v_{c}$ & $\mathrm{~m} / \mathrm{min}$ & 467 & 147 & 184 \\
\hline Posuw na ostrze $f_{z}$ & $\mathrm{~mm} / \mathrm{ostrze}$ & 0,006 & 0,04 & 0,145 \\
\hline Droga skrawania $l$ & $\mathrm{~m}$ & 241 & 80 & 24 \\
\hline Głębokość skrawania $a_{p}$ & $\mathrm{~mm}$ & 1 & 1 & 1 \\
\hline
\end{tabular}

\section{Metodyka pomiarów}

W celu wyznaczenia wpływu zużycia ostrzy w głowicy frezowej na chropowatość powierzchni obrobionej przeprowadzono wiele pomiarów. Do zmierzenia zużycia ostrza zastosowano optyczny system pomiarów bezpośrednich. Wzdłuż krawędzi skrawającej od strony pomocniczej powierzchni przyłożenia

a)

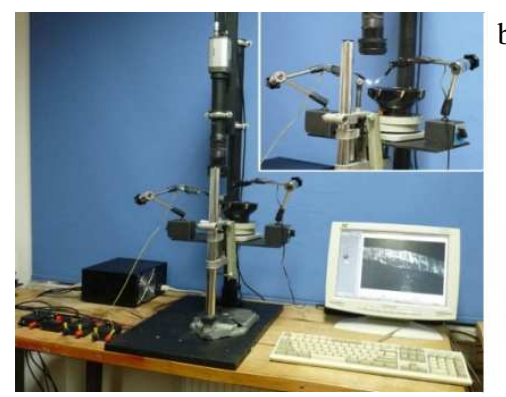

b)

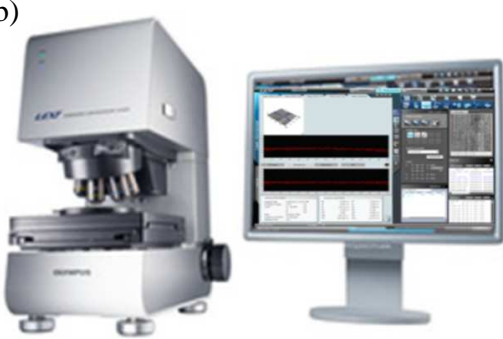

Rys. 2. Stanowisko badawcze do pomiaru zużycia ostrza (a), mikroskop konfokalny Olympus 3D LEXT OLS 4000 (b)

Fig. 2. Experimental set-up to measurement of tool wear (a), confocal microscope Olympus 3D LEXT OLS 4000 (b) 
zarejestrowano sekwencję obrazów ostrza. Po przetworzeniu danych z pozyskanej sekwencji obrazów cyfrowych zużycia pomocniczej powierzchni przyłożenia ostrza wyznaczono wartość wskaźnika $V B b_{s} \max$ z dokładnością $0,004 \mathrm{~mm}$ (rys. 2a). Pomiary powtarzano trzykrotnie. Pomiary chropowatości powierzchni obrobionej zostały wykonane za pomocą mikroskopu optycznego Olympus 3D LEXT OLS 4000 (rys. 2b) i wyznaczone programem TalyMap Platinum 4.0.

\section{Dyskusja wyników badań}

Zastosowana metoda pomiaru zużycia ostrza była metodą bezpośrednią, opierającą się na pomiarze jego cech geometrycznych. W tabeli 2 zamieszczono przykładowe obrazy powierzchni przyłożenia i powierzchni dogładzającej ostrzy skrawających dla najbardziej wysuniętej płytki w głowicy frezowej. Zgodnie $\mathrm{z}$ definicją zużycia powierzchni przyłożenia ostrza zamieszczoną w PN-ISO 8688-1:1996 wyróżnia się zużycie równomierne, nierównomierne i miejscowe. Dla każdego z nich wskazana norma podaje wartość kryterium ostrza, które dla typu zużycia miejscowego i małego okresu trwałości przyjmuje się jako 0,8 $\mathrm{mm}$. Zmierzone wartości wskaźnika $V B b_{s}$ max zużycia ostrzy dla wszystkich posuwów zostały pokazane w postaci wykresu słupkowego na rys. 3a. Wartości zużycia nie przekroczyły wartości dopuszczalnej. Wartość zużycia zależy od objętości skrawanego materiału, co pokazano na rys. 3c. Interesujący jest natomiast rozrzut wartości zużycia ostrza z uwzględnieniem warunków skrawania. Jak pokazano na rys. $3 b$, im mniejszy posuw na ostrze, tym większy jest rozrzut zużycia ostrzy w głowicy frezowej.

Tabela 2. Zarejestrowane obrazy cyfrowe zużycia ostrzy dla najbardziej wysuniętej płytki wymiennej w głowicy frezowej

Table 2. Digital images of the wear for the most advanced removable insert in face milling cutter

\begin{tabular}{|c|c|c|}
\hline $\begin{array}{l}\text { Posuw } \mathrm{f}_{\mathrm{z}} \\
\mathrm{mm} / \text { ostrze }\end{array}$ & Powierzchnia dogładzająca $b_{\mathrm{s}}$ przed frezowaniem & Powierzchnia dogładzająca $b_{s}$ po frezowaniu \\
\hline \multicolumn{3}{|l|}{0,006} \\
\hline \multicolumn{3}{|l|}{0,04} \\
\hline 0,145 & 8 & \\
\hline & tranm & \\
\hline
\end{tabular}



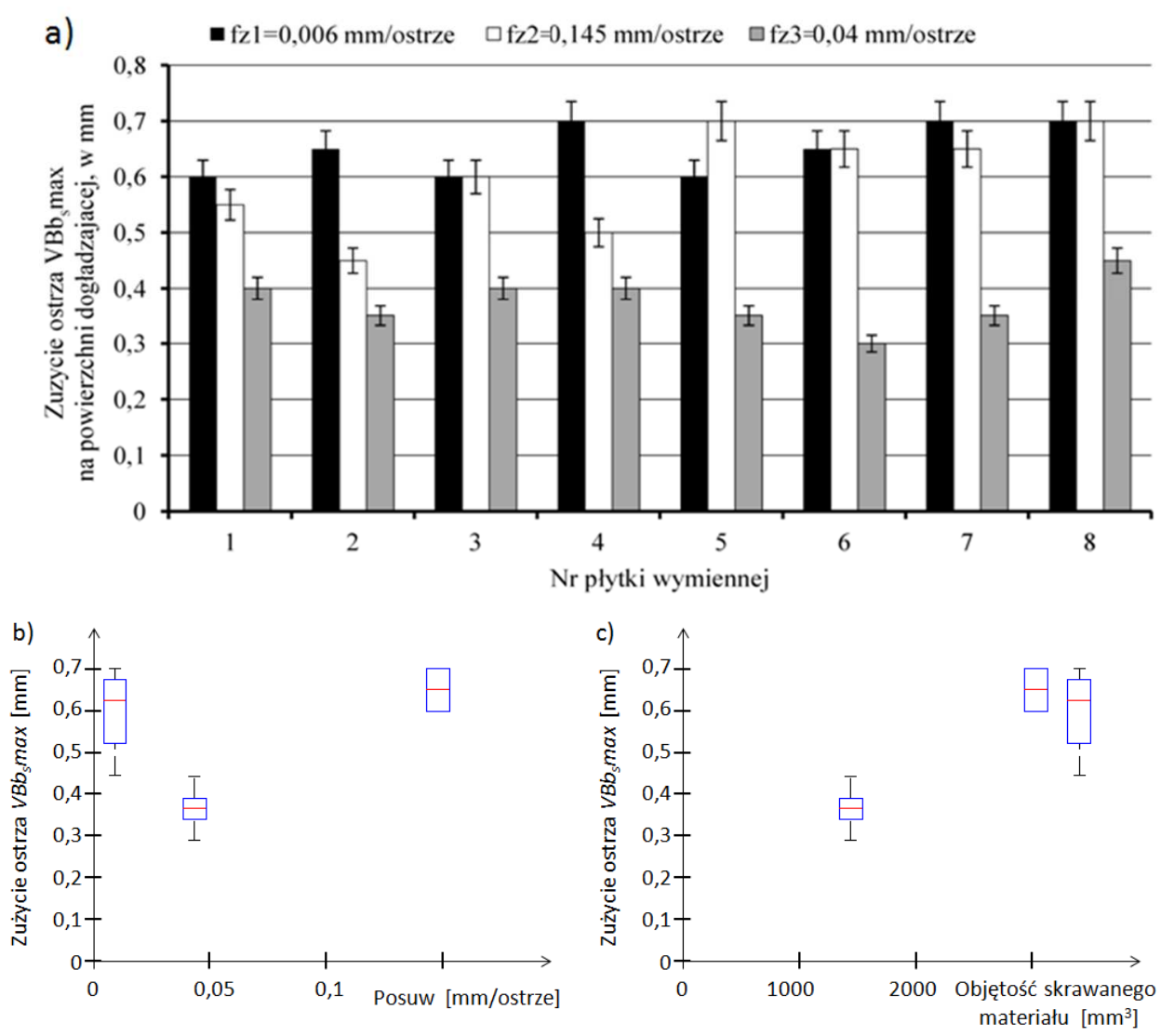

Rys. 3. Wartości wskaźnika $V B b_{s}$ max zużycia ostrzy w głowicy frezowej (a), zależność zużycia ostrza od posuwu (b), zależność zużycia ostrza od objętości skrawanego materiału (c)

Fig. 3. Values of $V B b_{s} \max$ wear index of cutting edges in face milling cutter (a), cutting edge wear $v s$. feed rate (b), cutting edge wear $v s$. volume of cut material (c)

Wartości zużycia ostrzy zestawione w funkcji bicia osiowego płytek skrawających w głowicy frezowej wskazują na to, że im większe wychylenie ostrza od linii nominalnej w głowicy frezowej (bicie osiowe), tym wartość zużycia ostrza jest większa (rys. 4). Analiza nachylenia krzywej zależności liniowej w funkcji posuwu na ostrze wskazuje na to, że im większy posuw na ostrze, tym wpływ ten jest większy.

Chropowatość powierzchni stopu tytanu zależy od posuwu na ostrze i prędkości skrawania oraz wielu innych czynników skrawania. Na rysunku 5 zamieszczono zmniejszenie wartości parametru $R a$ i $R z$ w zależności od posuwu na ostrze. Dla małej wartości posuwu, porównywalnej z minimalną grubością warstwy skrawanej, zauważono największe zróżnicowanie profilu. Można zaznaczyć, że warunki skrawania nie były korzystne również ze względu na relatywnie 

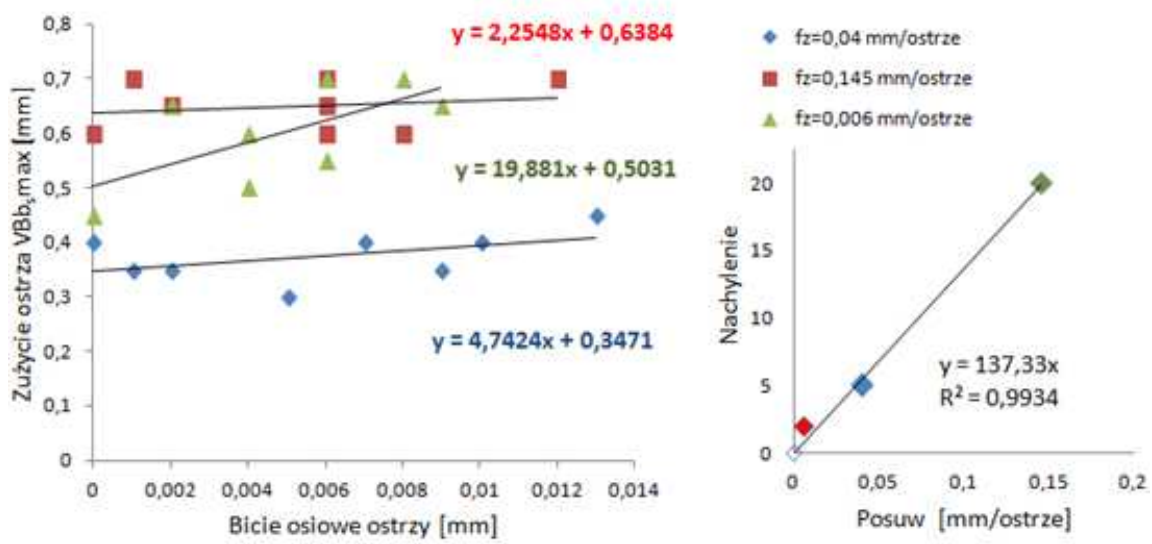

Rys. 4. Zużycie ostrzy w funkcji bicia osiowego płytek wymiennych w głowicy frezowej

Fig. 4. Cutting edge wear vs. run-out inserts in face milling cutter

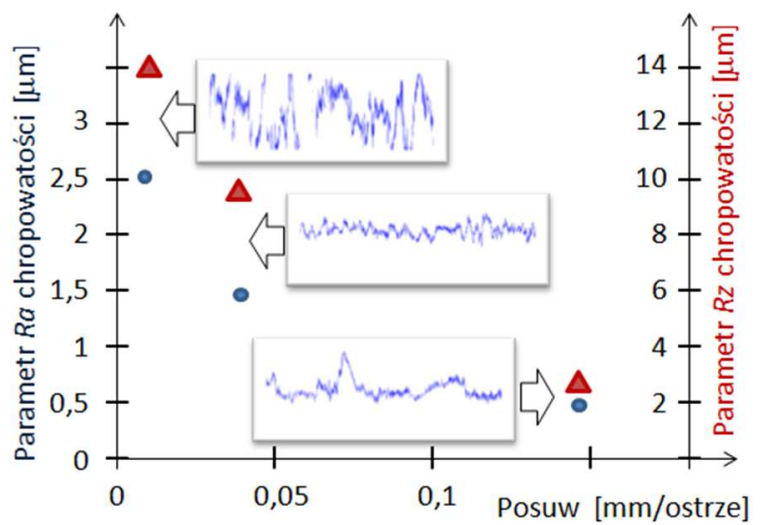

Rys. 5. Wartości chropowatości powierzchni obrobionej po frezowaniu stopu tytanu

Fig. 5. Values of milled surface roughness of titanium alloy

największą prędkość skrawania. Wartości obu parametrów: $R a$ i $R z$ są w tym przypadku największe. Przy największej wartości posuwu na ostrze i jednocześnie najmniejszej prędkości skrawania wartości parametrów $R a$ i $R z$ są najkorzystniejsze. Niejednorodności profilu powierzchni są efektem nakładania się śladów kolejnych ostrzy, które wykazują znaczne zużycie. Dla posuwu pośredniego ostrza skrawające miały najmniejsze zużycie, pracowały w średniej prędkości skrawania i frezowanie stopu tytanu przebiegało w warunkach najbardziej stabilnych. Ostrza kształtowały powierzchnię równomiernie i profilogram nie wykazał nagłych zróżnicowanych zmian wysokości nierówności.

Na rysunku 6 wizualizowano powierzchnię stopu tytanu w ujęciu 3D dla przebadanych posuwów. Jak można zauważyć, zestawione powierzchnie korespondują z profilogramami z rys. 5. Widoczne jest największe zróżnicowanie powierzchni dla najmniejszego posuwu, natomiast dla największego posuwu można zaobserwować miejscowe zakłócenia regularności śladów ostrzy. 
a)

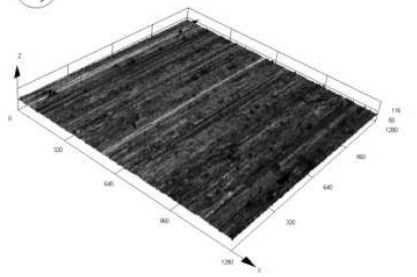

b)

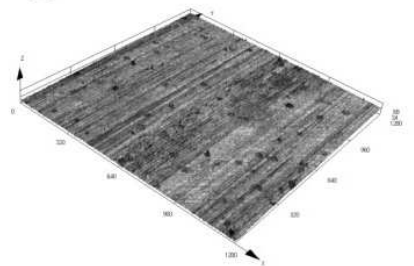

c)

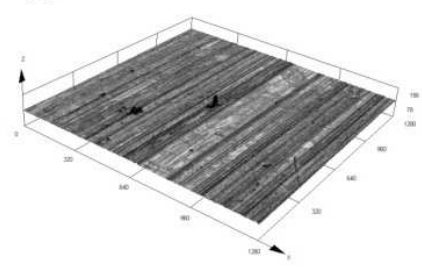

Rys. 6. Obrazy powierzchni obrobionych uzyskane z mikroskopu Olympus 3D LEXT OLS 4000 dla posuwu: a) $f_{z 1}=0,006$, b) $f_{z 2}=0,04$, c) $f_{z 3}=0,145 \mathrm{~mm} /$ ostrze

Fig. 6. Images of machined surfaces obtained with the use of Olympus 3D LEXT OLS 4000 microscope for feed: a) $f_{z 1}=0.006$, b) $f_{z 2}=0.04$, c) $f_{z 3}=0.145 \mathrm{~mm} /$ tooth

\section{Wnioski końcowe}

Do frezowania powierzchni płaskich trudno obrabialnego stopu tytanu zastosowano płytki skrawające z węglików spiekanych powlekanych. Płytki mocowano w głowicy frezowej, oceniano dla nich bicie osiowe, które później korelowano ze zużyciem ostrzy skrawających. Zużycie ostrzy w głowicy frezowej przebiegało bardzo intensywnie. Końcowe zużycie nie przekroczyło jednak wartości dopuszczalnej. Ślady zużycia na poszczególnych ostrzach narastały równomiernie. Zauważono niewielki wpływ bicia osiowego na zwiększenie intensywności zużycia na danym ostrzu. Powierzchnie obrobione stopu tytanu miały charakter typowy dla frezowania powierzchni płaskich, z wyraźnie widocznymi śladami posuwu na obrót i posuwu na ostrze. Badania chropowatości powierzchni ujawniły korzystny wpływ większego posuwu i mniejszej prędkości skrawania w badanym zakresie.

\section{Literatura}

[1] Davim J.P. (ed.): Machining of Titanium Alloys, Springer-Verlag, Berlin Heidelberg 2014.

[2] Ghani J.A., Che Haron C.H., Hamdan S.H., Md Said A.Y., Tomadi S.H.: Failure mode analysis of carbide cutting tools used for machining titanium alloy. Ceram Int., 39 (2013) 4449-4456.

[3] Hughes J., Sharman A., Ridgway K.: The effect of cutting tool material and edge geometry on tool life and workpiece surface integrity, Proc. Inst. Mech. Eng. Part B, J. Eng. Manuf., 220 (2006) 93-107.

[4] Jawaid A., Sharif S., Koksal S.: Evaluation of wear mechanisms of coated carbide tools when face milling titanium alloy, J. Mat. Proc. Technol., 99 (2000) 266-274.

[5] Sun J., Guo Y.: A comprehensive experimental study on surface integrity by end milling Ti-6Al-4V, J. Mat. Proc. Technol., 209 (2009) 4036-4042.

[6] Żurawski Ł., Pałka T., Zawada-Tomkiewicz A.: Poprawienie efektywność frezowania powierzchni płaskich. Obróbka Skrawaniem 6 - Efektywne wytwarzanie, Wrocław 2012. 


\section{INVESTIGATION OF EFFECT OFTOOL WEAR OF CUTTING EDGES OF FACE MILLING CUTTER ON SURFACE ROUGHNESS OF TITANIUM ALLOY}

\section{S u m m a r y}

This paper presents the results of milling tests of flat surfaces of WT22 (Ti-6Al-5Mo-5V-1Cr$-1 \mathrm{Fe}$ ) titanium alloy (hardness $40 \mathrm{HRC}$ ) with the use of titanium nitride coated sintered carbides. Selection of milling parameters and measurement methods was related to the analysis of the contact phenomena occurring during machining using the indexable tools, which form the machined surface as a result of the overlapping interactions. The face milling cutter with eight interchangeable inserts has a modern construction of blade tip in the form of an $\mathrm{Ab}_{\mathrm{s}}$ superfinish surface. The investigations of cutting edge wear and roughness of machined surface were carried out at three feed rates, taking into account face run-out of cutting edges.

Keywords: milling of flat surface, cutting edge wear, surface roughness of machined surface, machining of titanium alloy

DOI: $10.7862 / \mathrm{rm} .2017 .36$

Otrzymano/received:12.07.2017

Zaakceptowano/accepted: 24.09.2017 